\title{
Gastric Cancer by AJCC v8 Clinical Stage
}

National Cancer Institute

\section{Source}

National Cancer Institute. Gastric Cancer by AJCC v8 Clinical Stage. NCI Thesaurus. Code C133639.

A term that refers to the clinical staging of gastric cancer according to the American Joint Committee on Cancer, 8th edition. 